\title{
Perspectives on the modeling of the neuromusculoskeletal system to investigate the influence of neurodegenerative diseases on sensorimotor control
}

\author{
Leonardo Abdala Elias ${ }^{1,2 *}$, Débora Elisa da Costa Matoso', Renato Naville Watanabe ${ }^{3,4}$, \\ André Fabio Kohn 3,5 \\ ${ }^{1}$ Neural Engineering Research Laboratory, Department of Biomedical Engineering, School of Electrical and Computer \\ Engineering, University of Campinas, Campinas, SP, Brazil. \\ ${ }^{2}$ Center for Biomedical Engineering, University of Campinas, Campinas, SP, Brazil. \\ ${ }^{3}$ Biomedical Engineering Laboratory, Escola Politécnica, University of São Paulo, São Paulo, SP, Brazil. \\ ${ }^{4}$ Biomedical Engineering, Federal University of ABC, Santo André, SP, Brazil. \\ ${ }^{5}$ Graduate Neuroscience Program, University of São Paulo, São Paulo, SP, Brazil.
}

Abstract Introduction: The understanding of the neurophysiological mechanisms underlying movement control can be much furthered using computational models of the neuromusculoskeletal system. Biologically based multi-scale neuromusculoskeletal models have a great potential to provide new theories and explanations related to mechanisms behind muscle force generation at the molecular, cellular, synaptic, and systems levels. Albeit some efforts have been made to investigate how neurodegenerative diseases alter the dynamics of individual elements of the neuromuscular system, such diseases have not been analyzed from a systems viewpoint using multi-scale models. Overview and Perspectives: This perspective article synthesizes what has been done in terms of multi-scale neuromuscular development and points to a few directions where such models could be extended so that they can be useful in the future to discover early predictors of neurodegenerative diseases, as well as to propose new quantitative clinical neurophysiology approaches to follow the course of improvements associated with different therapies (drugs or others). Concluding Remarks: Therefore, this article will present how existing biologically based multi-scale models of the neuromusculoskeletal system could be expanded and adapted for clinical applications. It will point to mechanisms operating at different levels that would be relevant to be considered during model development, along with implications for interpreting experimental results from neurological patients.

Keywords Computational neuroscience, Neurodegenerative diseases, Neuromechanics, Spinal cord, ALS, Peripheral neuropathy.

\section{Introduction}

Experimental investigations have been conducted to provide data on the neuromechanics and control of movement in health and disease. Vertebrate preparations (other than humans) have provided a comprehensive assessment of molecular, cellular, and synaptic mechanisms

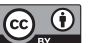

This is an Open Access article distributed under the terms of the Creative Commons Attribution License, which permits unrestricted use, distribution, and reproduction in any medium, provided the original work is properly cited.

How to cite this article: Elias LA, Matoso DEC, Watanabe RN, Kohn AF. Perspectives on the modeling of the neuromusculoskeletal system to investigate the influence of neurodegenerative diseases on sensorimotor control. Res Biomed Eng. 2018; 34(2):176-186. DOI: $10.1590 / 2446-4740.00117$

*Corresponding author: Universidade Estadual de Campinas, Av. Albert Einstein, 400, Office 228, Building A., Cidade Universitaria “Zeferino Vaz”, CEP 13083-852, Campinas, SP, Brazil. E-mail: leoelias@fee.unicamp.br

Received: 09 January 2018 / Accepted: 05 April 2018 involved in spinal cord neurophysiology and muscles (e.g., Burke et al., 1971; Eccles et al., 1957; Jankowska, 1992), along with the involvement of supraspinal pathways in motor control (for a review see Porter and Lemon, 1995). Parallel to animal experiments, human motor behavior has been extensively evaluated under different conditions. For instance, force and position control tasks have been used to evaluate the performance of the motor system and its constituent elements, such as motor units (De Luca and Hostage, 2010; Negro et al., 2016), spinal cord circuits (Magalhães et al., 2015; Yavuz et al., 2014), and the activity of descending tracts (Kristeva et al., 2007; Ushiyama et al., 2012).

Due to technical and ethical limitations, experiments performed on humans cannot provide detailed biophysical data on the neuromuscular elements involved. Therefore, their influence on system behavior - something of fundamental importance to understand how disease affects motor function - is poorly known. On the other hand, animal experiments have provided a detailed view 
on the mechanisms operating at different levels of the neuromuscular system and their putative involvement in force generation and control. More recently, genetically modified animal models have been adopted to investigate the underlying mechanisms of neurodegenerative diseases (e.g., Bouhy and Timmerman, 2013; Taylor et al., 2016). Another approach widely adopted by motor control research groups is the mathematical modeling of the neuromusculoskeletal system. Since the work of Hodgkin and Huxley (1952), quantitative models grounded on biophysical concepts have been used to provide additional clues on the mechanisms underlying neuronal function. More recently, multi-scale biologically based neuromuscular models have helped the interpretation of experimental results from humans, contributing with invaluable information on the neural bases of motor control (Allen and Elbasiouny, 2017; Elias et al., 2014; 2012; Farina et al., 2014; Nakajima et al., 2017; Niu et al., 2017; Schuurmans et al., 2009; Watanabe et al., 2013; Watanabe and Kohn, 2015; Williams and Baker, 2009b). The advantages of this approach might be summarized as: (1) the neuromechanics and control of movement can be associated to biophysical and electrophysiological properties of individual elements (e.g., neurons, synapses, sensory receptors, muscle fibers); (2) the individual behaviors of elements from a large set can be evaluated since there is no limitation regarding the recording of individual cell activity; (3) these models can be somewhat easily modified/adapted to represent changes experienced by the neuromuscular system during aging or pathological conditions.

To the best of our knowledge, none of the recent multi-scale models of the neuromusculoskeletal system attempted to investigate the influence of neurodegenerative diseases on motor control. This kind of research has the potential to improve our understanding of the fundamental mechanisms behind neuromechanical responses in diseased subjects from a functional point of view. Therefore, this perspective article is aimed at presenting an overview of existing multi-scale models of the human neuromusculoskeletal system and how they can be used or adapted/improved to provide new insights into neurodegenerative diseases. Most of the presentation in the subsequent sections will focus on a few representative aspects closer to our own experience with multi-scale modeling and their relation to specific neurodegenerative diseases.

\section{Overview of neuromusculoskeletal models}

in the last 25 years, different neuromusculoskeletal system models have been proposed to investigate human motor control. Part of these models include a detailed description of the musculoskeletal system, with physiological representations of muscle dynamics and the biomechanics of joints and limbs, but they only have a reduced biophysical description of the central nervous system (Laine et al., 2016; Nagamori et al., 2018; Raphael et al., 2010; Tsianos et al., 2014). Other models, on the other hand, focused on the representation of motor-unit pool physiology to investigate force control schemes (Fuglevand et al., 1993; Revill and Fuglevand, 2011). Here, we will focus on neuromusculoskeletal models that combine a biophysical description of the nervous system with a biologically plausible representation of the musculoskeletal system (e.g., Allen and Elbasiouny, 2017; Cisi and Kohn, 2008; Elias et al., 2014; Niu et al., 2017; Schuurmans et al., 2009; Williams and Baker, 2009b).

\section{Structure of a multi-scale neuromusculoskeletal model and its motor neurons}

Figure 1A provides an overview of the major structures encompassing the neuromusculoskeletal system and their interconnections. Some details of this figure depict the structures of possible mathematical models, e.g., related to a motor neuron (MN) soma and dendrites (Figure 1C), to an axon (Figure 1D) and to a muscle (schematic at the bottom of Figure 1B). The best described structure in existing multi-scale models is the spinal cord (schematic at the top of Figure 1B), whose major neural element is the MN. At least two different classes of MNs exist in the spinal cord (Manuel and Zytnicki, 2011): alpha $(\alpha)$ MNs, which innervate extrafusal muscle fibers; and gamma $(\gamma)$ MNs, which innervate intrafusal muscle fibers. Such $\alpha$ MNs are typically modeled mathematically on the basis of reduced compartmental models with at least one soma and one dendrite (Cisi and Kohn, 2008; Elias et al., 2014; 2012; Farina et al., 2014; Watanabe and Kohn, 2015; Watanabe et al., 2013; Williams and Baker, 2009b), with ionic channel dynamics represented using Hodgkin-Huxley $(\mathrm{HH})$ formalism (see an example of an $\alpha$-MN model in Figure 1C). Some studies adopted a point neuron model (single compartment) as a representation of $\alpha$ MNs (Niu et al., 2017; Schuurmans et al., 2009). Similarly, multi-compartment (>2) or morphologically realistic models are rarely adopted (Allen and Elbasiouny, 2017) mostly due to the large computational cost associated with their numerical solution, as well as the lack of a sufficient data on the parameter values that characterize the different MNs of any given pool, as well as the corresponding distributions of synaptic inputs along their dendritic trees.

As to the $\gamma$ MNs there is little information on their dynamics and biophysical properties. Therefore, to the best of our knowledge, none of the recent multi-scale 


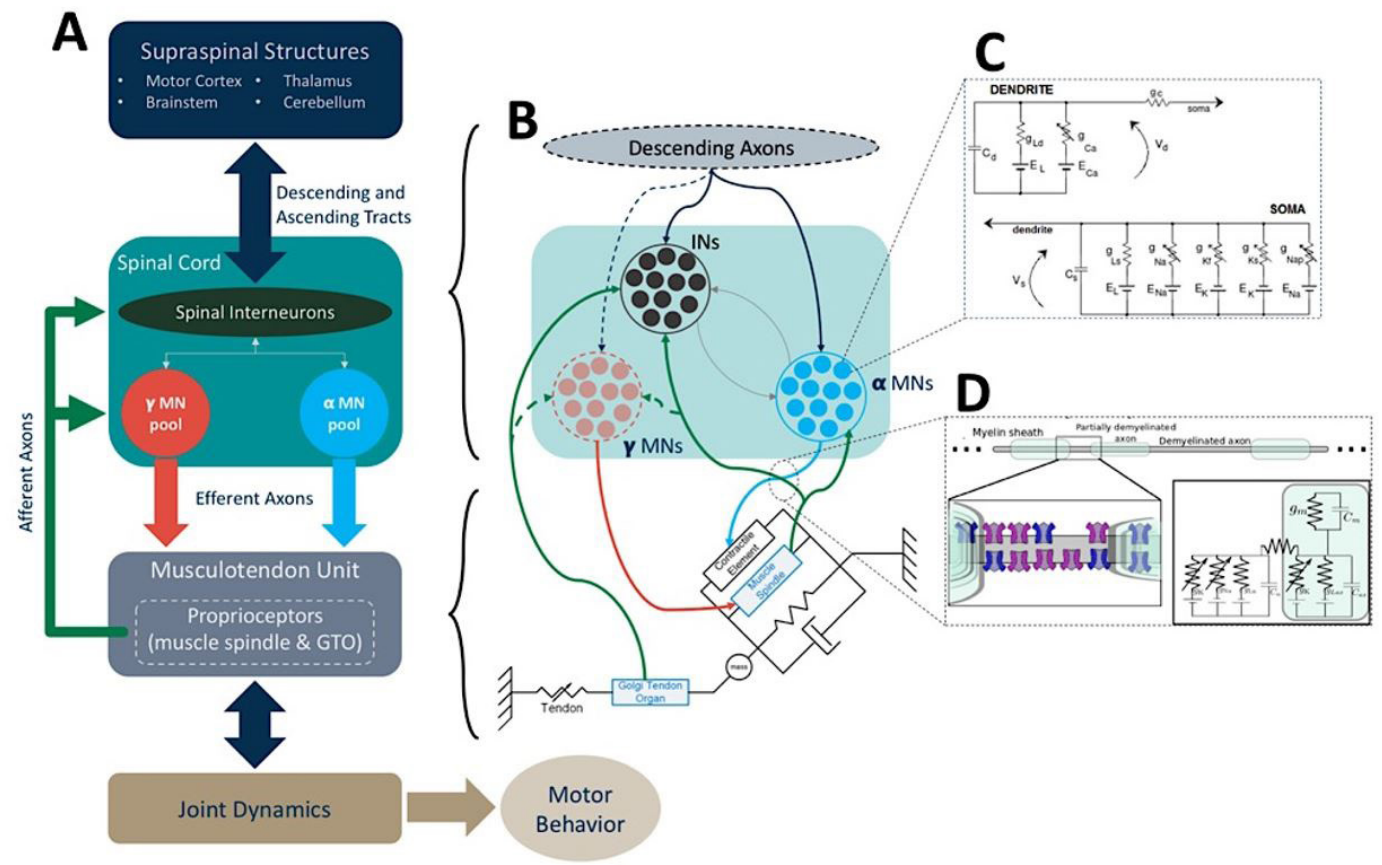

Figure 1. Hierarchical view of the neuromusculoskeletal system and its major structures. In color are the general aspects, and in thinner lines are three examples of possible modeling approaches to specific subsystems. (A) Overview (as a block diagram) of the neuromusculoskeletal system and the interactions between its elements. (B) A more detailed view of the spinal cord (top) and a typical Hill-type muscle model with muscle receptors (bottom) is shown to illustrate a common modeling approach for muscle functioning. Dashed lines represent either undetermined or underrepresented elements in current multi-scale mathematical models of the neuromuscular system. (C) Equivalent circuit of a typical $\alpha$-MN model, as used in mathematical models found in the literature. This two-compartment (soma-dendrite) model encompasses: membrane capacitance and leakage conductance $\left(C\right.$ and $g_{L}$, respectively); dendritic $\mathrm{Ca}^{++}$conductance $\left(g_{C a}\right)$; somatic $\mathrm{Na}^{+}$, fast $\mathrm{K}^{+}$, slow $\mathrm{K}^{+}$, and persistent $\mathrm{Na}^{+}$conductances $\left(g_{N a}, g_{K f}, g_{K s}\right.$, and $g_{N a p}$, respectively); and a coupling conductance $\left(g_{c}\right)$. Membrane $(V)$ and equilibrium $(E)$ potentials are also represented in the diagram. Subscripts $s$ and $d$ stand for somatic or dendritic elements, respectively. (D) The upper schematic figure depicts an axon with two healthy patches of myelin at the two ends and in between a thinner myelin segment followed by a total lack of a myelin segment. A node of Ranvier is shown magnified in a schematic at the lower left. At the bottom right there is a depiction of a possible electric circuit equivalent for a mathematical model of an axonal segment, showing at the left a basic circuit for the Ranvier node (with different voltage-dependent ionic channels) coupled to a myelinated equivalent circuit at the right. Acronyms: MN - Motor Neuron; IN - Interneuron; GTO - Golgi Tendon Organ.

neuromuscular models adopted a biophysically based mathematical representation of this class of MNs. Additionally, little is known about the convergence of synaptic inputs to these cells at the spinal cord (see dashed arrows in Figure 1B).

\section{Spinal interneurons}

Despite the great diversity of spinal interneurons (INs) (Jankowska and Hammar, 2002), only a few have been represented in multi-scale neuromuscular models, such as INs mediating Ia reciprocal inhibition (type Ia sensory afferents come from muscle spindles), group II excitation (type II sensory afferents come from muscle spindles), Ib inhibition (type Ib sensory afferents come from Golgi tendon organs), and recurrent inhibition by Renshaw cells. Sometimes, a tailor-made computer model simulator has been developed by a research group to investigate a specific interneuronal circuit. An example of such a model is that from Williams and Baker (2009a) which was used to evaluate a putative role of Renshaw cells in attenuating tremor. At other instances, a wider set of interneuronal circuits has been modeled and used in computer simulations, as in a recent study of neurophysiological mechanisms behind human postural control, which included interneuron circuit models of reciprocal inhibition, nonreciprocal or Ib inhibition, and group II excitation (Elias et al., 2014). Since descriptions of the morphology and electrophysiology of INs are scarce in the literature, such neurons have been mathematically modeled in a simplified way. Typically, interneurons have been represented by a single compartment encompassing passive and active membrane properties, as well as synaptic inputs (Cisi and Kohn, 2008; Elias et al., 2014; Williams and Baker, 2009a).

\section{Sensory receptors}

At least two kinds of sensory receptors have been included in neuromusculoskeletal models, the muscle spindle and the Golgi tendon organ, which provide position and force feedback. The activity of muscle spindle 
sensory afferents has been represented by simplified (Prochazka and Gorassini, 1998) or biophysically based models (Mileusnic et al., 2006). However, the great challenge in working with muscle spindle models is the setting of the fusimotor drive (static and dynamic), which is mostly unknown in humans and primates. Most of the studies adopt ad-hoc values for the fusimotor inputs to reproduce experimental data from cats and humans (Elias et al., 2014; Jalaleddini et al., 2017a; 2017b; Mileusnic et al., 2006; Niu et al., 2017). Albeit a comprehensive model of Golgi tendon organs (GTOs) has been proposed in the literature (Mileusnic and Loeb, 2006), multi-scale neuromusculoskeletal models have adopted phenomenological nonlinear models for GTO activity produced in response to force modulation (Lin and Crago, 2002).

The outputs of these receptors have been represented as analog signals that modulate conductances of spinal neurons (Schuurmans et al., 2009) or modulate the intensity of spike trains that affect the spinal neurons by postsynaptic potentials (Chaud et al., 2012).

\section{Supraspinal nervous system}

Despite their significant role in motor control, supraspinal structures (e.g., motor cortex, brainstem, cerebellum, basal ganglia) have been largely simplified in current neuromusculoskeletal models (see the dashed ellipse in Figure 1B). Large-scale models of brain circuits do exist (e.g., Eliasmith et al., 2012), but to the best of our knowledge, no study tried to merge these models and the existing multi-scale models of the neuromuscular system. So far, the activity of descending tracts has been represented by stochastic processes (either continuous or point processes) acting on spinal neurons. Also, it is worth noting that ascending sensory pathways to supraspinal structures are still absent in the present neuromuscular models.

\section{Synapses}

As to the synaptic dynamics, either alpha functions or kinetic models have been employed in neuromusculoskeletal models. The alpha functions have been used either as postsynaptic potentials themselves or as representing synaptic conductances (the latter are better representations of reality). The kinetic models represent the dynamics of reaction between neurotransmitter and receptor so that the synaptic conductances follow the amount of bound neurotransmitter to receptor at any given time. The main advantage of kinetic models (Destexhe et al., 1994) is their close relation with physiological processes associated with neurotransmitter release and binding to postsynaptic receptors. Some studies ignore the synaptic dynamics by representing the effective synaptic current reaching the soma as a stochastic process (Negro and Farina, 2011) or a superposition of sinusoids (Farina et al., 2014).

\section{Musculotendon units and joint biomechanics}

Hill-type models (at the bottom of Figure 1B) or some biologically plausible simplification have been adopted to represent musculotendon dynamics and force generation in multi-scale neuromuscular models (Elias et al., 2014; Nagamori et al., 2018; Niu et al., 2017; Schuurmans et al., 2009). These models are preferable to simple twitch representations (Fuglevand et al., 1993) since variations in muscle length and tendon tension are used as feedback variables in most scenarios (see the blue rectangles in Figure 1B). A great diversity of models has been proposed and evaluated in the literature (for a review see Tsianos and Loeb 2017; Valero-Cuevas et al., 2009) but they mostly represented isometric or quasi-isometric contractions. History-dependent muscle properties (such as short-range stiffness and yielding) are usually neglected in current multi-scale models of the neuromusculoskeletal system, thereby precluding a deeper investigation of muscle function (Tsianos et al., 2012). Therefore, more refined models should be considered in the future for better biological realism, such as models based on the known dynamics and energetics of cross-bridges (Tsianos et al., 2012; Zahalak, 1981). However, in some studies one is interested in the mapping of the MN pool inputs to the muscle force under the simplification of an open-loop system, i.e., without sensory feedback (Allen and Elbasiouny, 2017; Elias et al., 2012; Negro and Farina, 2011; Watanabe et al., 2013; Williams and Baker, 2009b). In such cases, force generation mechanisms can be simplified by linear (Fuglevand et al., 1993) or nonlinear (Raikova and Aladjov, 2002) models to represent a muscle twitch.

Once the muscle force is generated, the torque at a given joint can be calculated by considering muscle moment arm, which depends on joint position (Arnold et al., 2010). Studies on isometric force production do not consider joint dynamics, since no movement is produced in this case. To investigate more complex motor behaviors, Newton's laws of movement are used to derive joint dynamics (Elias et al., 2014; Loeb and Davoodi, 2016). Current multi-scale models, however, have tended to investigate single degree of freedom movements, since the solution of multi-dimensional multi-link biomechanical systems would require the calculation of an extremely large number of coupled differential equations (Durandau et al., 2018), leading to prohibitively long computation times when coupled to biophysically based neuronal dynamics. For the latter challenge, an interface between future multi-scale neuromuscular model simulators and multi-link dynamics packages should be created in order to optimize the usability of those two complex and complementary resources. 


\section{On the choice of model parameters}

Parameterization is a tough problem when dealing with the mathematical modeling of any biological system. In existing neuromuscular multi-scale models, the parameter values have been chosen both from experimental measurements from animals (mostly cats) and humans. For instance, morphological (e.g., somatic and dendritic areas) and electrophysiological parameters (e.g., resting and equilibrium potentials, ionic channel conductances) of $\alpha$ MNs were mostly based on traditional studies from type-identified cat motor units (Burke et al., 1971; Cullheim et al., 1987). There is some indication that cat spinal neurons behave similarly to their human counterparts (Jankowska and Hammar, 2002), so animal data can be used (with some care) for computer modeling of the human neuromuscular system. On the other hand, conduction velocities of motor and sensory axons can be somewhat easily estimated from nerve conduction studies in humans (Pierrot-Deseilligny and Burke, 2012). Some biomechanical parameters, such as muscle and tendon passive stiffness, as well as force-length and force-velocity relationships have been derived from cat experiments (Brown et al., 1996; Scott et al., 1996). More recently, imaging techniques (e.g., ultrasound) have been used to assess muscle fiber length, muscle pinnation angle, and moment arms in humans (Passmore et al., 2016).

Nonetheless, the lack of information regarding some parameters does not necessarily precludes a proper model parameterization. When the parameters are not available in the literature or cannot be easily assessed by experimentation the model can be carefully adjusted so that the behavior of individual or ensembles of elements match some experimental outcomes. For instance, the detailed mathematical descriptions of ionic and synaptic conductances in a MN membrane are not available, but the model parameters can be adjusted so that the frequency-to-current relation and the magnitude of post-synaptic potentials are similar to those observed in individual cells (e.g., Cisi and Kohn, 2008; Elias et al., 2012; Elias and Kohn, 2013). From a systems point of view, some results from motor control studies might be used as references to validate the choice of model parameters (see Elias et al., 2014; Watanabe et al., 2013).

\section{Current and prospective advances in the modeling of neurodegenerative diseases}

In the previous section, we briefly described the main efforts to represent the neuromusculoskeletal dynamics in terms of multi-scale mathematical models (from ion channels to motor behaviors). Here, we will describe recent studies that provide some data on how neurodegenerative diseases change behaviors of different variables or parameter values that could be useful for model building. Also, we will discuss how the changes in model structure or parameter values due to disease can be combined with existing neuromusculoskeletal models to support investigations on force or position control in pathological conditions.

\section{Motor neuron disease}

Motor neuron disease is a class of neurodegenerative disorders, amyotrophic lateral sclerosis (ALS) being the most common form (Bromberg, 2015). About 10\% of ALS cases are hereditary, and approximately $20 \%$ of these cases result from mutations in the $\mathrm{Cu} / \mathrm{Zn}$ superoxide-dismutase-1 (SOD-1) gene. As a consequence, recent advances in ALS pathophysiology come from experiments conducted in mutant SOD-1 mice (Taylor et al., 2016).

ALS affects both upper and lower MNs (see Figure 2), thereby significantly influencing volitional and reflexive control of movement. Degeneration of upper MNs reduces the cortical control of spinal circuits (circles 1 and 2 in Figure 2), including a decrease of corticomotoneuronal synaptic drive (Eisen et al., 1996; Fisher et al., 2012) and hyperreflexia due to reduced activation of inhibitory (glycinergic) V1 interneurons, such as Ia inhibitory INs and Renshaw cells (Martin and Chang, 2012; Raynor and Shefner, 1994). As to the lower MNs, their loss will produce muscle weakness and atrophy (circle 4 in Figure 2) (Vucic and Kiernan, 2009).

Animal experiments, primarily on $\alpha$ MNs, have provided biophysical foundations of ALS etiology. Kuo et al. (2005) showed that persistent $\mathrm{Na}^{+}$current is increased in both low- and high-threshold $\alpha$ MNs. However, hyperexcitability was observed only in high-threshold $\alpha$ MNs (more susceptible to neurodegeneration) due to a downregulation of outward currents. Additionally, Chang and Martin (2016) reported an abnormal expression of voltage-gated $\mathrm{Ca}^{++}$channels, which results in an increase in $\mathrm{Ca}^{++}$currents and, consequently, $\alpha \mathrm{MN}$ excitability. Conversely, other studies have provided evidence that intrinsic excitability of MNs are reduced during ALS development, both due to changes in MN morphology (Amendola and Durand, 2008) and electrophysiology (Delestrée et al., 2014). These changes in ionic channel expressions and cell morphology are closely linked to the genetic mutation (mostly SOD-1) experienced by the animal. However, MN degeneration might be also strengthened by an accumulation of intracellular $\mathrm{Ca}^{++}$, which increases cell toxicity (Nijssen et al., 2017). In humans, force control studies carried out in patients with ALS have shown an increased motor unit discharge variability (Piotrkiewicz and Hausmanowa-Petrusewicz, 


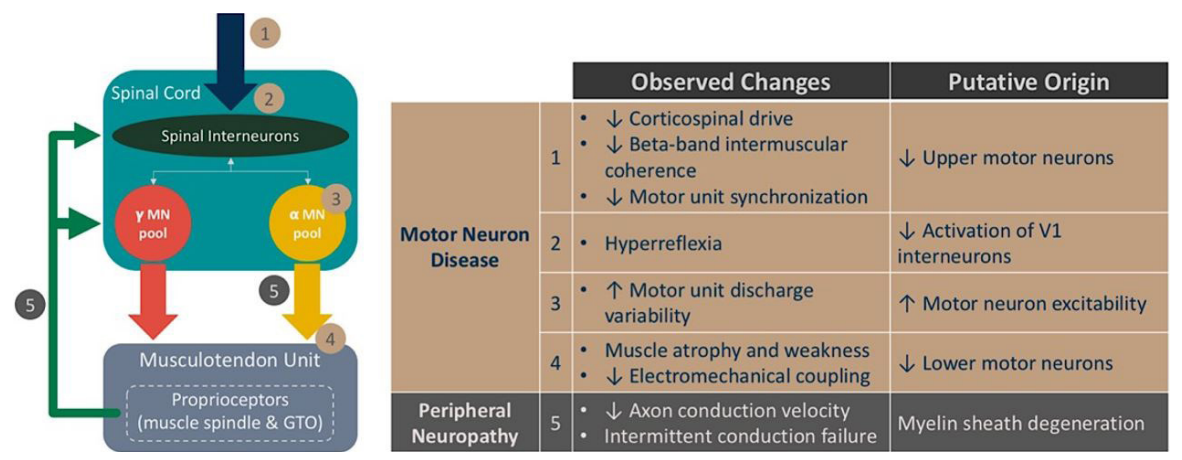

Figure 2. Observed changes and their putative origin in motor neuron disease and peripheral neuropathy. The circles represent the elements of the neuromuscular system affected during these neurodegenerative diseases.
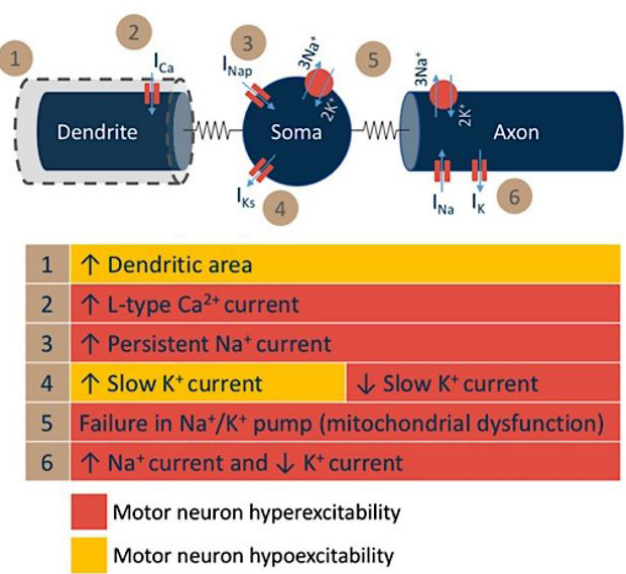

Figure 3. Schematic representation of modifications that might be performed or included in the models of $\alpha$ MNs to represent ALS pathophysiology. The circles represent the elements of a MN model that would be changed to represent different stages of ALS. Changes in model parameters might result in either MN hyper- (red) or hypoexcitability (yellow).

2011), altered axonal conduction velocity (Kanai et al., 2006), decreased beta-band intermuscular coherence (Fisher et al., 2012), and altered electromechanical muscle responses (Schmied et al., 1999). Figure 2 summarizes the observed changes observed in different stages of ALS and their putative origin.

From a computational neuroscience perspective, few studies have explored how ALS mechanisms influence $\alpha \mathrm{MN}$ dynamics. ElBasiouny et al. (2010) used morphological models to investigate the role of dendritic morphology and electrophysiological properties on the reduced excitability of $\alpha$ MNs in early stages of ALS. They found that increased dendritic area, along with a reduced somatic and dendritic membrane resistance, would explain both hypoexcitability and reduced synaptic efficacy observed in mutant SOD-1 MNs. Le Masson et al. (2014) proposed morphologically and biophysically plausible $\alpha \mathrm{MN}$ models encompassing mechanisms of bioenergetics (ATP production/consumption). They showed that deficits in ATP production [due to mitochondrial dysfunction (Lin and Beal, 2006)] will lead to a homeostatic imbalance, which increases intracellular $\mathrm{Ca}^{++}$concentration and induces a chronic membrane depolarization. High-threshold MNs were more prone to this altered excitability, since they have larger area and require more energy during spiking activity. The increased depolarization observed in these models, resulting from a less effective $\mathrm{Na}^{+} / \mathrm{K}^{+}$pump, can also explain the emergence of fasciculation, which is a common phenomenon in different stages of ALS (Eisen and Swash, 2001).

Neuromusculoskeletal models can be invaluable to study modifications in motor behaviors following ALS onset and progression. For this purpose, several changes observed in animal models and patients with ALS should be properly incorporated in different parts of the models. For instance, in $\alpha \mathrm{MN}$ models (see Figure 3), the dendritic morphology, electrophysiological properties (e.g., increased persistent currents, reduced membrane resistance), and bioenergetics might be altered/included to investigate how differences in excitability and synaptic efficacy of the modelled $\alpha \mathrm{MN}$ pool would influence force variability and motor unit discharge patterns. Also, the inclusion of motor axon dynamics seems to be an important step toward investigations on the emergence of fasciculation and how altered efferent conduction (Kanai et al., 2006) would influence motor tasks in different stages of ALS.

From a systems level, one might investigate how partial loss of the corticospinal tract (which might be modeled by a reduction in the numbers of independent point processes or a decrease in the effective synaptic current) would affect force generation and control. An important aspect that should also be considered during model parameterization is that the number of motor units is significantly decreased in ALS (Boe et al., 2007). In this view, the neuromusculoskeletal models can be used to predict the influence of altered excitability of 
spinal circuits in typical force or position control tasks. Experimental data from patients with ALS can be used to validate the models and to provide some insights on the biophysical mechanisms influencing motor control.

It is important to notice that ALS (like other neurodegenerative diseases) can also affect muscle properties and, consequently, joint dynamics. Schmied et al. (1999) showed that ALS patients exhibited a reduction in the electromechanical coupling, which was estimated as the ratio between motor unit twitch amplitude and the area of motor unit action potential from the extensor carpi radialis muscle. Also, the referred authors observed that muscle twitches were heterogeneous, i.e., several motor units exhibited an increased amplitude and time to peak, probably due to axon sprouting (reinnervation) following degeneration, while other motor units produced significantly lower muscle twitches. Therefore, any investigation concerning force or position control should take these muscular aspects into consideration too.

\section{Peripheral neuropathies}

Peripheral neuropathies are a group of diseases that cause axonal degeneration (see Figure 1D). Examples are Charcot-Marie-Tooth disease (Brennan et al., 2015), Guillain-Barré syndrome (Kuwabara and Yuki, 2013), chronic inflammatory demyelinating polyneuropathy (Mathey et al., 2015), and multifocal motor neuropathy (Priori et al., 2005). An important class of peripheral neuropathies is characterized by a progressive myelin degradation, which can affect both motor and sensory axons (circle 5 in Figure 2). Some of these demyelinating diseases are heredodegenerative, such as Charcot-Marie-Tooth (which affects both sensory and motor axons), while others are caused by infection, such as Guillain-Barré syndrome. In the latter, there may be a pure sensory, a pure motor, or a mixed sensory-motor axonal degeneration. The pathophysiological result, independent of the primary trigger, is a slowing of axonal action potential conduction, an intermittent or even a complete failure of its propagation (see Figure 2). In the former case the action potentials propagating along a nerve through slower conducting axons will lead to poorer functioning of the target tissue (e.g., muscle force rise time and peak values far from normal) or the whole neuromuscular subsystem [e.g., poorer motor control due to longer feedback and feedforward delays (Jauregui-Renaud, 2013; Nardone et al., 2006)].

Theoretical studies using computational models of healthy sensory and motor axons have investigated how the action potential discharge patterns are influenced by changes in axonal characteristics. For example, Howells et al. (2012) and McIntyre et al. (2002) found that the difference in motor and sensory axons are determined by differences in $\mathrm{K}^{+}$and $\mathrm{Na}^{+}$ionic channels.
Similarly, Bostock et al. (1991) studied the influence of the axon myelin sheath in action potential conduction. Further developments of this model lead to efforts to represent different neurodegenerative axonal diseases in individual axons. For instance, Stephanova and Dimitrov (2013) determined the correspondence between different types of axon demyelination and specific diseases (e.g., Guillain-Barré syndrome is caused by internodal focal demyelination). Another example is the influence of temperature on action potential conduction in patients with chronic inflammatory demyelinating polyneuropathy (Stephanova and Daskalova, 2015).

Departing from these previous studies, the next steps would be to integrate the mathematical models of axonal dynamics into multi-scale neuromuscular models. The computational load will increase substantially, but this will be compensated by the benefits of obtaining new data on the impacts of specific degenerative axonal diseases on motor control. For example, functional quantifiers such as force and position control as well as postural control as simulated for different levels of neurodegeneration may lead to novel clinical neurophysiology tools for discovering an early onset of a given disease and its progression in response to different interventions.

\section{Concluding remarks}

The extension of currently available multi-scale models of neuromusculoskeletal systems to represent diseased states has a promising role as an aid to improve the diagnosis and the therapy of many neurodegenerative pathologies. If correctly modeled, the action of a given disease on specific elements may be studied from a systems level. This can point to measurable changes in overall motor output (e.g., force variability, postural sway) that can be early indicators of disease and estimates of the ongoing outcome of a given therapy. The latter may be useful for optimizing specific therapeutic approaches from a functional standpoint.

Here we presented how multi-scale neuromuscular models can be extended to allow studies of two classes of neurodegenerative diseases on the basis of their pathophysiological features affecting different elements of the neuromuscular system. However, even if seen only in a more limited scope of the functioning of a healthy neuromuscular system, other structures and mechanisms should be included in current neuromusculoskeletal models to further our understanding about movement control (Loeb and Tsianos, 2015). Probably, the greatest challenge for future studies is to integrate models of supraspinal structures, such as the basal ganglia-thalamocortical circuit (Kumaravelu et al., 2016), to investigate how brain circuits interact with spinal cord circuits in normal and pathological conditions. This would improve considerably 
our capabilities of evaluating sensorimotor control in a much wider scope and, with adequate parameter changes, potentiate further studies of other neurological disorders, such as Parkinson's disease and stroke.

\section{Acknowledgements}

LAE was funded by Grants from FAEPEX/UNICAMP (proc. nos. 1483/14 and 3289/16) and CNPq (Brazilian NSF, proc. nos. 409302/2016-3 and 312442/2017-3). DECM was funded by FAPESP (Sao Paulo Research Foundation, proc. nos. 2015/14917-9 and 2017/11464-9). RNW was funded by FAPESP and CAPES (Coordination for the Improvement of Higher Education Personnel, proc. no. 2015/21819-3). AFK was funded by CNPq (proc. no. 303809/2016-7).

\section{References}

Allen JM, Elbasiouny SM. The effects of model composition design choices on high-fidelity simulations of motoneuron recruitment and firing behaviors. J Neural Eng. 2017; 15(3):036024. http://dx.doi.org/10.1088/1741-2552/aa9db5. PMid:29182156.

Amendola J, Durand J. Morphological differences between wildtype and transgenic superoxide dismutase 1 lumbar motoneurons in postnatal mice. J Comp Neurol. 2008; 511(3):329-41. http:// dx.doi.org/10.1002/cne.21818. PMid:18803237.

Arnold EM, Ward SR, Lieber RL, Delp SL. A model of the lower limb for analysis of human movement. Ann Biomed Eng. 2010; 38(2):269-79. http://dx.doi.org/10.1007/s10439009-9852-5. PMid:19957039.

Boe SG, Stashuk DW, Doherty TJ. Motor unit number estimates and quantitative motor unit analysis in healthy subjects and patients with amyotrophic lateral sclerosis. Muscle Nerve. 2007; 36(1):62-70. http://dx.doi.org/10.1002/mus.20784 . PMid:17455264.

Bostock H, Baker M, Reid G. Changes in excitability of human motor axons underlying post-ischaemic fasciculations: evidence for two stable states. J Physiol. 1991; 441(1):537-57. http:// dx.doi.org/10.1113/jphysiol.1991.sp018766. PMid:1667800.

Bouhy D, Timmerman V. Animal models and therapeutic prospects for Charcot-Marie-Tooth disease. Ann Neurol. 2013; 74(3):391-6. http://dx.doi.org/10.1002/ana.23987. PMid:23913540.

Brennan KM, Bai Y, Shy ME. Demyelinating CMT-what's known, what's new and what's in store? Neurosci Lett. 2015; 596:14-26. http://dx.doi.org/10.1016/j.neulet.2015.01.059. PMid:25625223.

Bromberg MB. Motor neuron disease in adults. New York: Oxford Univeristy Press; 2015.

Brown IE, Scott SH, Loeb GE. Mechanics of feline soleus. 2. Design and validation of a mathematical model. J Muscle Res Cell Motil. 1996; 17(2):221-33. http://dx.doi.org/10.1007/ BF00124244. PMid:8793724.
Burke RE, Levine DN, Zajac FE, Tsairis P, Engel WK. Mammalian motor units: physiological-histochemical correlation in three types in cat gastrocnemius. Science. 1971;174(4010):709-12. PMID: 4107849.

Chang Q, Martin LJ. Voltage-gated calcium channels are abnormal in cultured spinal motoneurons in the G93A-SOD1 transgenic mouse model of ALS. Neurobiol Dis. 2016; 93:78-95. http://dx.doi.org/10.1016/j.nbd.2016.04.009. PMid:27151771.

Chaud VM, Elias LA, Watanabe RN, Kohn AF. A simulation study of the effects of activation-dependent muscle stiffness on proprioceptive feedback and short-latency reflex. In: Proceedings of the 4th IEEE RAS/EMBS International Conference Biomedical Robotics and Biomechatronics; 2012; Rome. USA: IEEE; 2012. p. 133-8.

Cisi RRL, Kohn AF. Simulation system of spinal cord motor nuclei and associated nerves and muscles, in a web-based architecture. J Comput Neurosci. 2008; 25(3):520-42. http:// dx.doi.org/10.1007/s10827-008-0092-8. PMid:18506610.

Cullheim S, Fleshman JW, Glenn LL, Burke RE. ThreeDimensional architecture of dendritic trees in type-identified alpha-motoneurons. J Comp Neurol. 1987; 255(1):82-96. http:// dx.doi.org/10.1002/cne.902550107. PMid:3819011.

De Luca CJ, Hostage EC. Relationship Between Firing Rate and Recruitment Threshold of Motoneurons in Voluntary Isometric Contractions. J Neurophysiol. 2010; 104(2):103446. http://dx.doi.org/10.1152/jn.01018.2009. PMid:20554838.

Delestrée N, Manuel M, Iglesias C, Elbasiouny SM, Heckman CJ, Zytnicki D. Adult spinal motoneurones are not hyperexcitable in a mouse model of inherited amyotrophic lateral sclerosis. J Physiol. 2014; 592(7):1687-703. http://dx.doi.org/10.1113/ jphysiol.2013.265843. PMid:24445319.

Destexhe A, Mainen ZF, Sejnowski TJ. An efficient method for computing synaptic conductances based on a kinetic-model of receptor-binding. Neural Comput. 1994; 6(1):14-8. http:// dx.doi.org/10.1162/neco.1994.6.1.14.

Durandau G, Farina D, Sartori M. Robust real-time musculoskeletal modeling driven by electromyograms. IEEE Trans Biomed Eng. 2018; 65(3):556-64. PMid:28504931.

Eccles JC, Eccles RM, Lundberg A. Synaptic actions on motoneurones in relation to the two components of the group i muscle afferent volley. J Physiol. 1957; 136(3):527-46. http:// dx.doi.org/10.1113/jphysiol.1957.sp005778. PMid:13429518.

Eisen A, Entezari-Taher M, Stewart H. Cortical projections to spinal motoneurons: changes with aging and amyotrophic lateral sclerosis. Neurology. 1996; 46(5):1396-1396. http:// dx.doi.org/10.1212/WNL.46.5.1396. PMid:8628489.

Eisen A, Swash M. Clinical neurophysiology of ALS. Clin Neurophysiol. 2001; 112(12):2190-201. http://dx.doi.org/10.1016/ S1388-2457(01)00692-7. PMid:11738189.

ElBasiouny SM, Amendola J, Durand J, Heckman CJ. Evidence from computer simulations for alterations in the membrane biophysical properties and dendritic processing of synaptic inputs in mutant superoxide dismutase-1 motoneurons. J Neurosci. 2010; 30(16):5544-58. http://dx.doi.org/10.1523/ JNEUROSCI.0434-10.2010. PMid:20410108. 
Elias LA, Chaud VM, Kohn AF. Models of passive and active dendrite motoneuron pools and their differences in muscle force control. J Comput Neurosci. 2012; 33(3):515-31. http://dx.doi. org/10.1007/s10827-012-0398-4. PMid:22562305.

Elias LA, Kohn AF. Individual and collective properties of computationally efficient motoneuron models of types $\mathrm{S}$ and F with active dendrites. Neurocomputing. 2013; 99:521-33. http://dx.doi.org/10.1016/j.neucom.2012.06.038.

Elias LA, Watanabe RN, Kohn AF. Spinal mechanisms may provide a combination of intermittent and continuous control of human posture: predictions from a biologically based neuromusculoskeletal model. PLOS Comput Biol. 2014; 10(11):e1003944. http://dx.doi.org/10.1371/journal. pcbi.1003944. PMid:25393548.

Eliasmith C, Stewart TC, Choo X, Bekolay T, DeWolfT, Tang $\mathrm{Y}$, Rasmussen D. A large-scale model of the functioning brain. Science. 2012;30(611):338:1202-5. http://dx.doi.org/10.1126/ science. 1225266.

Farina D, Negro F, Dideriksen JL. The effective neural drive to muscles is the common synaptic input to motor neurons. J Physiol. 2014; 592(16):3427-41. http://dx.doi.org/10.1113/ jphysiol.2014.273581. PMid:24860172.

Fisher KM, Zaaimi B, Williams TL, Baker SN, Baker MR. Beta-band intermuscular coherence: a novel biomarker of upper motor neuron dysfunction in motor neuron disease. Brain. 2012; 135(Pt 9):2849-64. http://dx.doi.org/10.1093/ brain/aws 150. PMid:22734124.

Fuglevand AJ, Winter DA, Patla AE. Models of recruitment and rate coding organization in motor-unit pools. J Neurophysiol. 1993; 70(6):2470-88. http://dx.doi.org/10.1152/jn.1993.70.6.2470. PMid:8120594.

Hodgkin AL, Huxley AF. A quantitative description of membrane current and its application to conduction and excitation in nerve. J Physiol. 1952; 117(4):500-44. http://dx.doi.org/10.1113/ jphysiol.1952.sp004764. PMid:12991237.

Howells J, Trevillion L, Bostock H, Burke D. The voltage dependence of I h in human myelinated axons. J Physiol. 2012; 590(7):1625-40. http://dx.doi.org/10.1113/jphysiol.2011.225573. PMid:22310314.

Jalaleddini K, Nagamori A, Laine CM, Golkar MA, Kearney RE, Valero-Cuevas FJ. Physiological tremor increases when skeletal muscle is shortened: implications for fusimotor control. J Physiol. 2017a; 595(24):7331-46. http://dx.doi.org/10.1113/ JP274899. PMid:29023731.

Jalaleddini K, Niu C, Chakravarthi Raja S, Sohn WJ, Loeb G, Sanger T, Valero-Cuevas F. Neuromorphic meets neuromechanics, Part II: The role of fusimotor drive. J Neural Eng. 2017b; 14(2):158-62. PMid:28094764.

Jankowska E, Hammar I. Spinal interneurones; how can studies in animals contribute to the understanding of spinal interneuronal systems in man? Brain Res Brain Res Rev. 2002; 40(1-3):19-28. http://dx.doi.org/10.1016/S0165-0173(02)001856. PMid:12589903.

Jankowska E. Interneuronal relay in spinal pathways from proprioceptors. Prog Neurobiol. 1992; 38(4):335-78. http:// dx.doi.org/10.1016/0301-0082(92)90024-9. PMid:1315446.
Jauregui-Renaud K. Postural balance and peripheral neuropathy. In Souayah N (Ed.). Peripheral neuropathy - a new insight into the mechanism, evaluation and management of a complex disorder. Rijeka: InTech; 2013. p. 125-46. http://dx.doi. org/10.5772/55344.

Kanai K, Kuwabara S, Misawa S, Tamura N, Ogawara K, Nakata M, Sawai S, Hattori T, Bostock H. Altered axonal excitability properties in amyotrophic lateral sclerosis: impaired potassium channel function related to disease stage. Brain. 2006; 129(Pt 4):953-62. http://dx.doi.org/10.1093/brain/ aw1024. PMid:16467388.

Kristeva R, Patino L, Omlor W. Beta-range cortical motor spectral power and corticomuscular coherence as a mechanism for effective corticospinal interaction during steady-state motor output. Neuroimage. 2007; 36(3):785-92. http://dx.doi org/10.1016/j.neuroimage.2007.03.025. PMid:17493837.

Kumaravelu K, Brocker DT, Grill WM. A biophysical model of the cortex-basal ganglia-thalamus network in the 6-OHDA lesioned rat model of Parkinson's disease. J Comput Neurosci. 2016; 40(2):207-29. http://dx.doi.org/10.1007/s10827-0160593-9. PMid:26867734

Kuo JJ, Siddique T, Fu R, Heckman CJ. Increased persistent $\mathrm{Na}+$ current and its effect on excitability in motoneurones cultured from mutant SOD1 mice. J Physiol. 2005; 563(Pt 3):843-54. http://dx.doi.org/10.1113/jphysiol.2004.074138. PMid:15649979.

Kuwabara S, Yuki N. Axonal Guillain-Barré syndrome: concepts and controversies. Lancet Neurol. 2013; 12(12):1180-8. http:// dx.doi.org/10.1016/S1474-4422(13)70215-1. PMid:24229616.

Laine CM, Nagamori A, Valero-Cuevas FJ. The dynamics of voluntary force production in afferented muscle influence involuntary tremor. Front Comput Neurosci. 2016; 10:1-14. http://dx.doi.org/10.3389/fncom.2016.00086. PMid:27594832.

Le Masson G, Przedborski S, Abbott LF. A computational model of motor neuron degeneration. Neuron. 2014; 83(4):975-88. http://dx.doi.org/10.1016/j.neuron.2014.07.001. PMid:25088365.

Lin CC, Crago PE. Neural and mechanical contributions to the stretch reflex: a model synthesis. Ann Biomed Eng. 2002; 30(1):54-67. http://dx.doi.org/10.1114/1.1432692. PMid:11874142.

Lin MT, Beal MFF. Mitochondrial dysfunction and oxidative stress in neurodegenerative diseases. Nature. 2006; 443(7113):78795. http://dx.doi.org/10.1038/nature05292. PMid:17051205.

Loeb G, Davoodi R. Musculoskeletal mechanics and modeling. Scholarpedia. 2016; 11(11):12389. http://dx.doi.org/10.4249/ scholarpedia.12389.

Loeb GE, Tsianos GA. Major remaining gaps in models of sensorimotor systems. Front Comput Neurosci. 2015; 9:1-11. http://dx.doi.org/10.3389/fncom.2015.00070.

Magalhães FH, Elias LA, Silva CR, Lima FF, Toledo DR, Kohn AF. D1 and D2 inhibitions of the soleus H-Reflex are differentially modulated during plantarflexion force and position tasks. PLoS One. 2015; 10(11):e0143862. http:// dx.doi.org/10.1371/journal.pone.0143862. PMid:26599909.

Manuel M, Zytnicki D. Alpha, beta and gamma motoneurons: functional diversity in the motor system's final pathway. J 
Integr Neurosci. 2011; 10(3):243-76. http://dx.doi.org/10.1142/ S0219635211002786. PMid:21960303.

Martin LJ, Chang Q. Inhibitory synaptic regulation of motoneurons: a new target of disease mechanisms in amyotrophic lateral sclerosis. Mol Neurobiol. 2012; 45(1):30-42. http://dx.doi. org/10.1007/s12035-011-8217-x. PMid:22072396.

Mathey EK, Park SB, Hughes RAC, Pollard JD, Armati PJ, Barnett MH, Taylor BV, Dyck PJB, Kiernan MC, Lin CS-Y. Chronic inflammatory demyelinating polyradiculoneuropathy: from pathology to phenotype. J Neurol Neurosurg Psychiatry. 2015; 86(9):973-85. http://dx.doi.org/10.1136/jnnp-2014309697. PMid:25677463.

McIntyre CC, Richardson AG, Grill WM. Modeling the excitability of mammalian nerve fibers: influence of afterpotentials on the recovery cycle. J Neurophysiol. 2002; 87(2):995-1006. http:// dx.doi.org/10.1152/jn.00353.2001. PMid:11826063.

Mileusnic MP, Brown IE, Lan N, Loeb GE. Mathematical models of proprioceptors. I. Control and transduction in the muscle spindle. J Neurophysiol. 2006; 96(4):1772-88. http:// dx.doi.org/10.1152/jn.00868.2005. PMid:16672301.

Mileusnic MP, Loeb GE. Mathematical models of proprioceptors. II. Structure and function of the Golgi tendon organ. J Neurophysiol. 2006; 96(4):1789-802. http://dx.doi.org/10.1152/ jn.00869.2005. PMid:16672300.

Nagamori A, Laine CM, Valero-Cuevas FJ. Cardinal features of involuntary force variability can arise from the closed-loop control of viscoelastic afferented muscles. PLOS Comput Biol. 2018; 14(1):e1005884. http://dx.doi.org/10.1371/journal. pcbi.1005884. PMid:29309405.

Nakajima T, Tazoe T, Sakamoto M, Endoh T, Shibuya S, Elias LA, Mezzarane RA, Komiyama T, Ohki Y. Reassessment of non-monosynaptic excitation from the motor cortex to motoneurons in single motor units of the human biceps brachii. Front Hum Neurosci. 2017; 11:19. http://dx.doi.org/10.3389/ fnhum.2017.00019. PMid:28194103.

Nardone A, Grasso M, Schieppati M. Balance control in peripheral neuropathy: are patients equally unstable under static and dynamic conditions? Gait Posture. 2006; 23(3):364-73. http:// dx.doi.org/10.1016/j.gaitpost.2005.04.002. PMid:15896962.

Negro F, Farina D. Decorrelation of cortical inputs and motoneuron output. J Neurophysiol. 2011; 106(5):2688-97. http://dx.doi.org/10.1152/jn.00336.2011. PMid:21795617.

Negro F, Yavuz UŞ, Farina D. The human motor neuron pools receive a dominant slow-varying common synaptic input. J Physiol. 2016; 594(19):5491-505. http://dx.doi.org/10.1113/ JP271748. PMid:27151459.

Nijssen J, Comley LH, Hedlund E. Motor neuron vulnerability and resistance in amyotrophic lateral sclerosis. Acta Neuropathol. 2017; 133(6):863-85. http://dx.doi.org/10.1007/s00401-0171708-8. PMid:28409282.

Niu CM, Jalaleddini K, Sohn WJ, Rocamora J, Sanger T, Valero-Cuevas F. Neuromorphic meets neuromechanics PART I: the methodology and implementation. J Neural Eng. 2017; 14(2):025001. http://dx.doi.org/10.1088/1741-2552/aa593c. PMid:28084217.
Passmore E, Lai A, Sangeux M, Schache AG, Pandy MG. Application of ultrasound imaging to subject-specific modelling of the human musculoskeletal system. Meccanica. 2016

Pierrot-Deseilligny E, Burke D. The circuitry of the human spinal cord: spinal and corticospinal mechanisms of movement. Cambridge: Cambridge University Press; 2012. http://dx.doi. org/10.1017/CBO9781139026727.

Piotrkiewicz M, Hausmanowa-Petrusewicz I. Motoneuron afterhyperpolarisation duration in amyotrophic lateral sclerosis. J Physiol. 2011; 589(Pt 11):2745-54. http://dx.doi.org/10.1113/ jphysiol.2011.204891. PMid:21486815.

Porter R, Lemon R. Corticospinal function and voluntary movement. Oxford: Oxford University Press; 1995. http:// dx.doi.org/10.1093/acprof:oso/9780198523758.001.0001.

Priori A, Bossi B, Ardolino G, Bertolasi L, Carpo M, NobileOrazio E, Barbieri S. Pathophysiological heterogeneity of conduction blocks in multifocal motor neuropathy. Brain. 2005; 128(Pt 7):1642-8. http://dx.doi.org/10.1093/brain/ awh513. PMid:15888541.

Prochazka A, Gorassini M. Models of ensemble firing of muscle spindle afferents recorded during normal locomotion in cats. J Physiol. 1998; 507(Pt 1):277-91. http://dx.doi. org/10.1111/j.1469-7793.1998.277bu.x. PMid:9490851.

Raikova RT, Aladjov HT. Hierarchical genetic algorithm versus static optimization - investigation of elbow flexion and extension movements. J Biomech. 2002; 35(8):1123-35. http:// dx.doi.org/10.1016/S0021-9290(02)00031-3. PMid:12126671.

Raphael G, Tsianos GA, Loeb GE. Spinal-like regulator facilitates control of a two-degree-of-freedom wrist. J Neurosci. 2010; 30(28):9431-44. http://dx.doi.org/10.1523/ JNEUROSCI.5537-09.2010. PMid:20631172.

Raynor EM, Shefner JM. Recurrent inhibition is decreased in patients with amyotrophic lateral sclerosis. Neurology. 1994; 44(11):2148-53. http://dx.doi.org/10.1212/WNL.44.11.2148. PMid:7969975.

Revill AL, Fuglevand AJ. Effects of persistent inward currents, accommodation, and adaptation on motor unit behavior: a simulation study. J Neurophysiol. 2011; 106(3):1467-79. http:// dx.doi.org/10.1152/jn.00419.2011. PMid:21697447.

Schmied A, Pouget J, Vedel J. Electromechanical coupling and synchronous firing of single wrist extensor motor units in sporadic amyotrophic lateral sclerosis. Clin Neurophysiol. 1999; 110(5):960-74. http://dx.doi.org/10.1016/S13882457(99)00032-2. PMid:10400212.

Schuurmans J, de Vlugt E, Schouten AC, Meskers CGM, de Groot JH, van der Helm FCT. The monosynaptic Ia afferent pathway can largely explain the stretch duration effect of the long latency M2 response. Exp Brain Res. 2009; 193(4):491-500. http://dx.doi.org/10.1007/s00221-008-1647-7. PMid:19048240.

Scott SH, Brown IE, Loeb GE. Mechanics of feline soleus. 1. Effect of fascicle length and velocity on force output. J Muscle Res Cell Motil. 1996; 17(2):207-19. http://dx.doi.org/10.1007/ BF00124243. PMid:8793723.

Stephanova DI, Daskalova M. Electrotonic potentials in simulated chronic inflammatory demyelinating polyneuropathy 
at $20^{\circ} \mathrm{C}-42^{\circ} \mathrm{C}$. J Integr Neurosci. $2015 ; 14(2): 235-52$. http:// dx.doi.org/10.1142/S0219635215500119. PMid:25916252.

Stephanova DI, Dimitrov B. Computational neuroscience: simulated demyelinating neuropathies and neuronopathies. Boca Raton, FL: CRC Press; 2013. http://dx.doi.org/10.1201/b14589.

Taylor JP, Brown RH Jr, Cleveland DW. Decoding ALS: from genes to mechanism. Nature. 2016; 539(7628):197-206. http:// dx.doi.org/10.1038/nature20413. PMid:27830784.

Tsianos GA, Goodner J, Loeb GE. Useful properties of spinal circuits for learning and performing planar reaches. J Neural Eng. 2014; 11(5):56006. http://dx.doi.org/10.1088/1741$2560 / 11 / 5 / 056006$.

Tsianos GA, Loeb GE. Muscle and limb mechanics. Compr Physiol. 2017;7(2):429-62. https://doi.org/10.1002/cphy.c160009.

Tsianos GA, Rustin C, Loeb GE. Mammalian muscle model for predicting force and energetics during physiological behaviors. IEEE Trans Neural Syst Rehabil Eng. 2012; 20(2):117-33. http:// dx.doi.org/10.1109/TNSRE.2011.2162851. PMid:21859633.

Ushiyama J, Masakado Y, Fujiwara T, Tsuji T, Hase K, Kimura A, Liu M, Ushiba J. Contraction level-related modulation of corticomuscular coherence differs between the tibialis anterior and soleus muscles in humans. J Appl Physiol. 2012; 112(8):1258-67. http://dx.doi.org/10.1152/japplphysiol.01291.2011. PMid:22302959.

Valero-Cuevas FJ, Hoffmann H, Kurse MU, Kutch JJ, Theodorou EA. Computational models for neuromuscular function. IEEE Rev Biomed Eng. 2009; 2:110-35. http://dx.doi.org/10.1109/ RBME.2009.2034981. PMid:21687779.
Vucic S, Kiernan MC. Pathophysiology of neurodegeneration in familial amyotrophic lateral sclerosis. Curr Mol Med. 2009; 9(3):255-72. http://dx.doi.org/10.2174/156652409787847173. PMid:19355908.

Watanabe RN, Kohn F. Fast oscillatory commands from the motor cortex can be decoded by the spinal cord for force control. J Neurosci. 2015; 35(40):13687-97. http://dx.doi.org/10.1523/ JNEUROSCI.1950-15.2015. PMid:26446221.

Watanabe RN, Magalhães FH, Elias LA, Chaud VM, Mello EM, Kohn AF. Influences of premotoneuronal command statistics on the scaling of motor output variability during isometric plantar flexion. J Neurophysiol. 2013; 110(11):2592-606. http://dx.doi.org/10.1152/jn.00073.2013. PMid:24027105.

Williams ER, Baker SN. Renshaw cell recurrent inhibition improves physiological tremor by reducing corticomuscular coupling at $10 \mathrm{~Hz}$. J Neurosci. 2009a; 29(20):6616-24. http:// dx.doi.org/10.1523/JNEUROSCI.0272-09.2009. PMid:19458232.

Williams ER, Baker SN. Circuits generating corticomuscular coherence investigated using a biophysically based computational model. I. Descending Systems. J Neurophysiol. 2009b; 101(1):3141. http://dx.doi.org/10.1152/jn.90362.2008. PMid:19019981.

Yavuz SU, Mrachacz-Kersting N, Sebik O, Berna Ünver M, Farina D, Türker KS. Human stretch reflex pathways reexamined. J Neurophysiol. 2014; 111(3):602-12. http://dx.doi.org/10.1152/ jn.00295.2013. PMid:24225537.

Zahalak GI. A distribution-moment approximation for kinetic theories of muscular-contraction. Math Biosci. 1981; 55(12):89-114. http://dx.doi.org/10.1016/0025-5564(81)90014-6. 